\title{
Sulfur record of rising in marine sulfate levels 800 million years ago
}

\author{
XiAnguO LANG ${ }^{1}$, SONGZHUO Li ${ }^{1}$, HAORAN MA ${ }^{2}$, Bing \\ SHEN $^{2}$ \\ ${ }^{1}$ Institute of Sedimentary Geology, Chengdu University of \\ Technology, Chengdu 610059, China \\ ${ }^{2}$ School of Earth and Space Sciences, Peking University, \\ Beijing 100871, China
}

The Earth experienced the second rise of atmospheric oxygen levels $\left(p \mathrm{O}_{2}\right)$ in the late Neoproterozoic that is collectively known as the Neoproterozoic oxidation event (NOE). Lines of geochemical evidence suggest the rise of $p \mathrm{O}_{2}$ commenced at ca.820-750 million years ago (Ma). However, marine oxidants levels during the initial stage of the NOE remain unclear. In order to address this, we report organic carbon $\left(\delta^{13} \mathrm{C}_{\mathrm{org}}\right)$ and pyrite sulfur $\left(\delta^{34} \mathrm{~S}_{\mathrm{py}}\right)$ isotopes of the Hetong and Gongdong formations (ca.800-720 Ma) in Nanhua Basin, South China. The Hetong and Gongdong formations, mainly consisting of turbiditic laminated mudstone and thin bedded sandstone, were deposited in deep water envrionment. $\delta^{13} \mathrm{C}_{\text {org }}$ of these formations varies between $-35.2 \%$ and $-25.8 \%$ (average: $-31.7 \%$, $n=119$ ), with total organic carbon content (TOC) ranging from 0.03 wt.\% to 0.68 wt.\% (average: 0.23 wt.\%, $\mathrm{n}=119$ ). $\delta^{34} \mathrm{~S}_{\mathrm{py}}$ remains invariant $(\sim-10 \%)$ throughout the Hetong Formtion and shows secular variation $\left(-20.2 \% 0^{-}+9.8 \%\right)$ in stratigraphy in the Gongdong Formation. In addition, all samples have relatively high pyrite content (average: $0.99 \mathrm{wt} . \%, \mathrm{n}=95$ ). Here we use numerical models to simulate the observed sulfur record. The modeling results suggest the microbial sulfate reduction is occurred within sediments and $\delta^{34} S_{p y}$ is mainly controlled by TOC, sedimentation rate and seafloor redox. The results also show that the invariant $\delta^{34} \mathrm{~S}_{\mathrm{py}}$ with high pyrite content from the Hetong Formation indicate a moderate marine sulfate level of $\sim 5 \mathrm{mM}$. Wide variations in $\delta^{34} \mathrm{Spy}_{\mathrm{py}}$ from the Gongdong Formation are resulted from local changes in sedimentation rate rather than fluctuations of seawater redox. Our study confirms the increasing of marine oxidants levels $\sim 800$ million years ago and suggests that $\delta^{34} S_{\text {py-pyrite content }}$ system is more applicable in quantifying ancient sulfur cycles. 